\title{
QUALITY OF AIR AND WATER IN DENTAL HEALTHCARE SETTINGS DURING PROFESSIONAL TOOTHCLEANING
}

\author{
Giuseppe A. M essano ${ }^{1}$, Aisha A. A. Sofan ${ }^{2}$, Stefano Petti ${ }^{1}$ \\ ${ }^{1}$ SAPIENZA UNIVERSITY, DEPARTMENT OF PUBLIC HEALTH AND INFECTIOUS DISEASES, ROME, ITALY; \\ ${ }^{2}$ AL THAWRA HOSPITAL, DEPARTMENT OF DENTISTRY AND MAXILLOFACIAL SURGERY, SANA'A, YEMEN
}

\begin{abstract}
Introduction. Professional toothcleaning with ultrasonic scaler produces microbial aerosols. These microorganisms come from dental unit waterlines (DUWLs) -thus potentially including opportunistic pathogens, or from patients -thus potentially including human pathogens. Aim. To investigate the association between levels and quality of contamination of air samples and DUWLs during professional toothcleaning, thus providing information regarding the nature of air contamination produced by ultrasonic scaler use.

M aterial and methods. Before treating the first patient of the day, 100 $m L$ of water was aseptically collected from the DUWL designated for the ultrasonic scaler, water was not disinfected or flushed. Aliquots were plated on Plate Count Agar to determine total viable flora (TVF) and Charcoal-Yeast Extract Agar supplemented with $\alpha$ Growth Supplement to determine Legionella. Two sets of settle plates were placed on the tray in front of the patient, one before and another during patient treatment to determine TVF and Legionella. The association between TVF and Legionella levels and prevalence in DUWLs and in air samples was assessed using correlation coefficients.

Results. 82 testing occasions were performed. The mean TVF levels in DUWLs and air were 21.2 (95\% confidence interval, 95CI, 13.8-32.6) CFU/mL and 12.4 (95CI, 9.7-15.8) CFU/plate/h, respectively. The mean Legionella detection rates were 1.2\% (DUWLs) and $0 \%$ (air). Correlations between air and water TVF and Legionella were not significant.

Conclusion. Air contamination during ultrasonic scaler use was frequent and high, but it was not associated with DUWL contamination, suggesting that airborne microorganisms could come from patients and be potentially pathogens for humans.
\end{abstract}

Key words: dental unit waterline, airborne infection, Legionella, environment, infection control

\section{Introduction}

Dental patients and dental healthcare providers (DHCPs) are exposed to pathogenic microorganisms including viruses, such as Hepatitis B and Hepatitis C virus and Human

\footnotetext{
Address for correspondence:

Dr. Giuseppe AlessioMessano

Department of Public Health and Infectious Diseases

Sapienza University

P.le Aldo Moro 5, 00185 Rome, Italy

Phone/Fax: +3906 49914667

Email: giuseppe.messano@yahoo.it
}

Immunodeficiency Virus, bacteria, such as Mycobacterium tuberculosis and staphylococci, and other microorganisms, which colonize or infect the upper aero-digestive tract or are circulating in blood. The consequent risk for infection among patients and staff is only in part determined and is principally due to direct contact of patient's DHCP's blood and/or biological fluids with the blood the counterpart, indirect contact through sharp instruments contaminated by blood and/or biological fluids, inhalation of airborne spatter or aerosols ${ }^{1,2}$. - One specific category of microorganisms are aquatic bacteria which colonize the dental unit waterlines (DUWLs) through the development of a multi-species biofilm. Some of these microorganisms, such as Legionella pneumophila serogroup ${ }^{1}$, Pseudomonas aeruginosa and non-tubercular M ycobacterium spp., are opportunistic pathogens which generally infect susceptible individuals in peculiar environmental conditions ${ }^{3,4}$. Biofilm formation into DUWL is promoted by water stagnation, which occurs when the dental unit is not used for long periods of time as it may happen during weekends or holidays, by presence of organic material, necessary for bacterial nutrition, and by mild microclimate, typical of the environment of the healthcare settings $s^{3,5-7}$. The dental turbine is the most important vehicle responsible for the spread in

(C) 2013 Faculty of Medicine in Niš. Clinic of Dentistry in Niš. All rights reserved / (C) 2013 Medicinski fakultet Niš. Klinika za stomatologiju Niš. Sva prava zadržana 
the environment of microorganisms contained into DUWLs. These microorganisms could be members of aquatic biofilm of DUWLs, including the aforementioned opportunistic pathogens, and microorganisms from human secretions and blood aspirated during negative pressure generated when the turbine stops rotating ${ }^{8-10}$. For this reason, microorganisms are frequently detected in air samples from dental healthcare settings during routine practice. The level of air contamination tends to decrease few hours after the end of activity ${ }^{11-14}$.

Dental turbine is not the only dental instrument which emits contaminated water in the environment, as air-water syringe and, principally, ultrasonic scaler also are implicated. Ultrasonic equipment, generally preferred to the manual instruments because faster and less traumatic for periodontal tissues, causes a considerable increase in the production of microbial aerosol and spatter ${ }^{15-19}$. There is no scientific evidence which supports the association between risk for infection from aquatic opportunistic pathogens among DHCPs and patients due to the use of ultrasonic scaler ${ }^{2,3}$. Nevertheless, such a risk cannot be minimized, particularly in public healthcare settings where special patients are treated, such as immune-deficient individuals, elderly, oral cancer patients, etc., who are at high infection risk from nosocomial pathogens which are able to survive in the environment ${ }^{20}$.

\section{Aim}

In order to investigate whether air contamination during ultrasonic scaler was associated with aquatic microorganisms coming from contaminated DUWLs, the aim of this study was to assess the level of contamination of air samples and DUWLs during professional toothcleaning in public multi-chair dental healthcare settings.

\section{Material and methods}

\section{Setting}

The study was made in the dental section of the healthcare service of an Italian Military Force. This is a multi-chair unit where dental hygienist students from the Sapienza University of Rome (Italy) may perform their training period. During the days of the microbial samplings, professional toothcleaning was the only type of dental service which was provided. Water from DUWLs was not disinfected, although the dental staff regularly followed the guidelines for infection control in dental healthcare settings provided in 2003 by the Centres for Disease Control and Prevention (Atlanta, US). More specifically, ultrasonic scalers were steam autoclaved at every use and water was flushed for $30 \mathrm{sec}$ at the beginning of the working session ${ }^{1}$. The study protocol was approved by the Ethic Committee of the Sapienza University.

\section{Assessment of contamination of water samples from DUWLs}

Water sample $(100 \mathrm{~mL})$ from the DUWL designated for the ultrasonic scaler was aseptically collected into a sterile bottle with screw cap before professional toothcleaning of the first patient of the working session. Water was not flushed before sampling and when water was collected windows and doors were kept closed.

The sample was transported to the laboratory in a refrigerated bag and processed within one hour. $1 \mathrm{~mL}$ was plated on Plate Count Agar (PCA - Becton Dickinson Italia, Buccinasco, Italy) for the determination of total viable aerobic mesophilic heterotrophic bacteria (i.e., total viable flora, TVF). Plates were incubated 5 days at $37^{\circ} \mathrm{C}$. Colonies were counted and the level of TVF in water was expressed as colony forming units $(\mathrm{CFU}) / \mathrm{mL}$. In order to assess water quality, the Statement on Dental Unit Waterline of the American Dental Association (ADA - available at, http://www.ada.org/1856. aspx, last accessed February 20th, 2013) was followed: "by the year 2000, water delivered to patients during nonsurgical dental procedures consistently contains no more than $200 \mathrm{CFU} / \mathrm{ml}$ of aerobic mesophilic heterotrophic bacteria at any point in time in the unfiltered output of the dental unit". A ccording to this threshold, water was classified into good and bad quality. The TVF detection level of the present method was of $1 \mathrm{CFU} / \mathrm{mL}$.

The remaining $99 \mathrm{~mL}$ were filtered (nitrocellulose filters, pore size $0.22 \mu \mathrm{m}$ ) and the filter was plated on to Charcoal-Yeast Extract Agar (CYE - Oxoid, Basingstoke, 
England) supplemented with Legionella BCYE- $\alpha$ Growth Supplement (BCYE - Oxoid), for the determination of Legionella. BCYE plates were incubated 10 days at $37^{\circ} \mathrm{C}$ with $5 \% \mathrm{CO} 2$. Colonies with typical Legionella morphology were sub-cultured using CYE and BCYE and only those grown on BCYE and not grown on CYE were presumptively classified as Legionella ${ }^{7}$. Samples which yielded at least one presumptive Legionella colony were classified as positive for Legionella. The Legionella detection level of the present method was of $0.01 \mathrm{CFU} / \mathrm{mL}$.

\section{Assessment of air contamination}

Microbial contamination of air was assessed by passive sampling using two settle plates (diameter, $9 \mathrm{~cm}$ ), one was exposed for $1 \mathrm{~h}$ before treatment of the first patient of the working session, the other was exposed for $1 \mathrm{~h}$ during and after patient toothcleaning.

Plates were put on the tray in front of the patient at $1 \mathrm{~m}$ distance from patient's head. Two sets of plates were made, one set containing PCA, the other set containing BCYE. PCA plates were incubated 2 days at $37^{\circ} \mathrm{C}$. After incubation period they were counted and the level of air contamination produced by spatter was calculated by the difference between the count reported during toothcleaning and the count reported before toothcleaning ${ }^{21}$. Thelevel of TVF in air was expressed as CFU/plate/h. In order to assess air quality, a threshold level of $25 \mathrm{CFU} /$ plate/h was chosen and air samples were classified into good and bad quality ${ }^{11}$.

BCYE plates were incubated 10 days at $37^{\circ} \mathrm{C}$ with 5\% CO2. Colonies with typical Legionella morphology were sub-cultured in CYE and BCYE and only those grown on BCYE and not grown on CYE were presumptively classified as L egionella?.

\section{Statistical analysis}

Prevalence of air and water samples of bad quality was estimated. Correlation between air and water quality was assessed using parametric and non-parametric tests. More specifically, air and water TVF counts were log transformed to normalize data (the value 0.5 was added to all counts in order to obtain reliable values when $\mathrm{TVF}=0$ ) and the Pearson's correlation coefficient " $r$ " was assessed. The nonparametric Spearman's correlation coefficient rho $(\rho)$ was used to assess correlation between $\mathrm{good} / \mathrm{bad}$ quality of air and water.

Prevalence of presumptive Legionella spp. in air and water also was estimated and correlation between L egionella in air and water samples was assessed using Spearman's $\rho$.

A significance level of $95 \%$ was chosen.

\section{Results}

Eighty-two patients were treated, 34 males and 48 females aged between 13 and 85 years. The duration of the interventions ranged between 15 and $60 \mathrm{~min}$, with an average duration time of $35 \mathrm{~min}$ (data not in Table).

TVF in water samples from DUWLs ranged between undetected and $544 \mathrm{CFU} / \mathrm{mL}$, with mean level $21 \mathrm{CFU} / \mathrm{mL}$ and prevalence of bad quality samples, according to ADA, of $81.7 \%$ (Table 1). Legionella spp. was detected in one sample, providing a prevalence estimate of $1.2 \%$ positive samples (Table 2 ).

TVF in spatter ranged between undetected and $93 \mathrm{CFU} /$ plate/h with a mean level of 12 $\mathrm{CFU} /$ plate/h and prevalence of bad quality samples of 72 (Table 1). Legionella spp. was never detected (Table 2).

No correlation was found between water and air contamination by aerobic mesophilic heterotrophic flora in level and prevalence of bad quality samples (Table 1). The same result was reported for Legionella spp. (Table 2).

Table 1. Aerobic mesophilic heterotrophic flora (total viable flora, TVF) detected in water and air samples during professional toothcleaning with ultrasonic scaler. Mean TVF levels (geometric mean, 95\% confidence interval between parentheses) in water from DUWLs and in air. Prevalence of bad quality water (bad quality, $\geq 200 \mathrm{CFU} / \mathrm{mL}$ ) and air (bad quality, $\geq 25 \mathrm{CFU} /$ plate/h). Correlation between air and water quality (Pearson's correlation coefficient $r$ for counts and Spearman's correlation coefficient $\rho$ for bad quality samples).

\begin{tabular}{lll}
\hline & geometric mean & bad quality prevalence \\
\hline water from DUWLs & $21.23(13.83-32.60) \mathrm{CFU} / \mathrm{mL}$ & $81.7 \%(73.3-90.1)$ \\
air & $12.39(9.71-15.81) \mathrm{CFU} / \mathrm{plate} / \mathrm{h}$ & $72.0 \%(62.2-81.7)$ \\
correlation & $\mathrm{r}=0.01(\mathrm{p}=0.95)$ & $\rho=0.54(\mathrm{p}=0.25)$ \\
\hline
\end{tabular}


Table 2. Prevalence of presumptive Legionella spp. (95\% confidence interval between parentheses) detected in water and air samples during professional toothcleaning with ultrasonic scaler. Correlation between air and water samples Spearman's $\rho$ correlation coefficient).

\begin{tabular}{ll}
\hline \multicolumn{2}{c}{ presumptive Legionella spp. prevalence } \\
\hline water from DUWLs & $1.2 \%(<0.0-3.6)$ \\
air & $0.0 \%$ \\
correlation & $\rho=0,01(\mathrm{p}=0.99)$ \\
\hline
\end{tabular}

\section{Discussion}

The present study is one of the papers presented at the workshop "Advances in Infection Epidemiology and Control in Dental Healthcare Settings", Department of Public Health and Infectious Diseases, Sapienza University, Rome, Italy on February 9th, 2013 $22-28$.

Data from literature suggest that the use of ultrasonic scaler is probably the most important source of airborne microbial contamination. Indeed, the level of aerosol contamination during this type of treatment is three times higher than during the other dental treatments ${ }^{16}$. It is possible, therefore, that routine use of ultrasonic scaler may pose DHCPs and, specifically, dental hygienists at risk for infection, although environmental contamination does not necessarily lead to high infection risk ${ }^{2}$. Prolonged exposure to ultrasonic scaler use is already a source for occupational disease, as it has a demonstrated ability to produce hearing impairment among DHCPs $^{29,30 .}$

The present study was designed to investigate the quality and type of microbial contamination of air due to the use of ultrasonic scaler. The risk for infection associated with environmental contamination in dental healthcare settings depends on several variables. One of them, probably the principal factor, is the nature of microorganisms responsible for contamination. Indeed, microorganisms are broadly classifiable into obligate and opportunistic pathogens. Virulence of obligate pathogens is usually thought to evolve in reciprocal selection with humans. Therefore, infection is an implicit characteristic of these microorganisms, which have low-minimum infective doses and are highly contagious. The situation is different for opportunistic pathogens, which are commensal bacteria, such as methicillin-resistant Staphylococcus aureus, or environmental bacteria, such as Legionella. These microorganisms are able to survive in the environment for long time in certain cir cumstances $^{31}$, thus suggesting that they could be even more dangerous for human heal th than obligate pathogens. However, virulence of opportunistic pathogens decreases In their natural ecological niche because of life history tradeoffs and random accumulation of mutations that impair human virulence under relaxed selection $^{32}$. These conjectures suggest that the potential risk for infection due to air contamination depends upon the nature of microorganisms. Indeed, if microorganisms detected in air come from DUWLs, the risk for infection is probably low and limited to immune-depressed individuals and/or invasive interventions. Conversely, if microorganisms come from the patients under treatment, the risk for infection could be high.

The data of this study suggest that in the present healthcare setting there was no association between microbial levels in air and in water from DUWLs. Although the number of bad quality samples was high among both in air and DUWLs, the mesophilic heterotrophic bacteria detected in air were probably not the same as those detected in water. These data are corroborated by previous studies. One of them found that Legionella and Mycobacterium spp. microorganisms detected into DUWLs were not aerosolized during professional toothcleaning and the majority of airborne bacteria were not the same as those detected in DUWLs ${ }^{33}$. A nother study demonstrated that roughly $50 \%$ airborne bacteria detected in healthcare settings during treatment are presumptive oral streptococci ${ }^{19}$. Although oral streptococci are frequently detected in DUWLs using adequate cultivation and sampling methods 9,10 , the level detected in DUWLs is so low that it is not comparable with the level detected in air, thus suggesting that oral streptococci detected in air and those detected in water from DUWLs come from patients under treatment. 


\section{Conclusion}

These data suggest that air contamination during toothcleaning with ultrasonic scaler is relatively frequent and high and it is not correlated with DUWL contamination. It could be speculated that while water microorganisms are environmental bacteria, potentially opportunistic pathogens, air microorganisms could be commensals or obligate pathogens and may pose a risk for airborne infection transmission among dental staff and patients. 


\section{LITERATURA / REFERENCES}

1. Kohn WG, Collins AS, Cleveland $J \mathrm{~L}$ et al. Guidelines for infection control in dental health-care settings, 2003. MMWR Recomm Rep 2003;52(RR17):1-61.

2. Petti S, Polimeni A. The rationale of guidelines for infection control in dentistry: precautionary principle or acceptable risk? Infect Control Hosp Epidemiol 2010;31(12):1308-10.

3. Pankhurst CL, Coulter WA. Do contaminated dental unit waterlines pose a risk of infection? J Dent 2007;35(9):712-20.

4. O'Donnell MJ, Boyle MA, Russell RJ, Coleman DC. Management of dental unit waterline biofilms in the 21 st century. Future Microbiol 2011;6(10):1209-26.

5. Barbeau J. Waterborne biofilms and dentistry: the changing face of infection control. J Can Dent Assoc 2000;66(10):539-41.

6. Walker JT, Marsh PD. Microbial biofilm formation in DUWS and their control using disinfectants. J Dent 2007;35(9):721-30.

7. Petti S, Iannazzo S, Tarsitani G. Allogenic succession between Pseudomonas and Legionella in the water distribution system of a dental hospital. Ann Microbiol 2004;54(1):25-30.

8. Walker JT, Bradshaw DJ, Finney $M$ et al. $\mathrm{M}$ icrobiological evaluation of dental unit water systems in general dental practice in Europe. Eur J Oral Sci 2004;112(5):412-8.

9. Petti S, Tarsitani G. Detection and quantification of dental unit water line contamination by oral streptococci. Infect Control Hosp Epidemiol 2006;27(5):504-9.

10. Petti S, Moroni C, Messano GA, Polimeni A. Detection of oral streptococci in dental unit water lines after therapy with air turbine handpiece: biological fluid retraction more frequent than expected. Future Microbiol 2013;8(3):413-21.

11. Castiglia P, Liguori G, Montagna MT et al. Italian multicenter study on infection hazards during dental practice: control of environmental microbial contamination in public dental surgeries. BMC Public Health 2008;8:187.

12. Szymańska J, Dutkiewicz J. Concentration and species composition of aerobic and facultatively anaerobic bacteria released to the air of a dental operation area before and after disinfection of dental unit waterlines. Ann Agric Environ Med 2008;15(2):301-7.

13. Rautemaa R, Nordberg A, Wuolijoki-Saaristo $\mathrm{K}$, Meurman JH. Bacterial aerosols in dental practic -a potential hospital infection problem? J Hosp Infect 2006;64(1):76-81.

14. Kimmerle H, Wiedmann-Al-Ahmad M, Pelz K, Wittmer A, Hellwig E, Al-A hmad A. A irborne microbes in different dental environments in comparison to a public area. Arch Oral Biol 2012;57(6):689-96.

15. Gross KB, Overman PR, Cobb C, Brockmann S. A erosol generation by two ultrasonic scalers and one sonic scaler. A comparative study. J Dent Hyg 1992;66(7):314-8.

16. Grenier D. Quantitative analysis of bacterial aerosols in two different dental clinic environments. Appl Environ Microbiol 1995;61(8):3165-8.

17. King TB, Muzzin KB, Berry CW, Anders LM The effectiveness of an aerosol reduction device for ultrasonic scalers. J Periodontol 1997;68(1):45-9.
18. Harrel SK, Barnes JB, Rivera-Hidalgo F. Aerosol and splatter contamination from the operative site during ultrasonic scaling. J Am Dent Assoc 1998;129(9):1241-9.

19. Bennett AM, Fulford MR, Walker JT, Bradshaw DJ, Martin MV, Marsh PD. Microbial aerosols in general dental practice. Br Dent J 2000;189(12):664-7.

20. Petti S, Polimeni A. Risk of methicillin-resistant Staphylococcus aureus transmission in the dental healthcare setting: a narrative review. Infect Control Hosp Epidemiol 2011;32(11):1109-15.

21. Petti S, Iannazzo S, Tarsitani G. Comparison between different methods to monitor the microbial level of indoor air contamination in the dental office. Ann Ig 2003; 15(5):725-33

22. Messano GA, Masood M, Palermo P, Petti S. Predictors of Legionella occurrence in dental unit waterlines of a highly colonized dental hospital. Acta Stomatol Naissi 2013; 29(67): 1236-41; doi: 10.5937/ asn1367236M

23. Messano GA, Masood M, Palermo P, Petti S. Prevalence of reactive tuberculin skin test in dental healthcare workers and students. Acta Stomatol Naissi 2013; 29(67): 1242-48; doi: 10.5937/asn1367242M.

24. Petti S, Sofan AAA, Messano GA. Streptococcus pneumoniae carriage rate in healthy preadolescent dental patients. Acta Stomatol Naissi 2013; 29(67): 1249-54; doi: 10.5937/asn1367249P.

25. Messano GA, De Bono V, Architrave R, Petti S. Environmental and gloves' contamination by staphylococci in dental healthcare settings. Acta Stomatol Naissi 2013; 29(67): 1255-59; doi: 10.5937/ asn1367255M

26. Messano GA. Bacterial and fungal contamination of dental hygienists' hands with and without finger rings. Acta Stomatol Naissi 2013; 29(67): 1260-64; doi: 10.5937/asn1367260M .

27. Petti S, Messano GA, Polimeni A, Dancer S]. Effect of cleaning and disinfection on naturally contaminated clinical contact surfaces. A cta Stomatol Naissi 2013; 29(67): 1265-72; doi: 10.5937/asn1367265P.

28. Petti S, Messano GA, Scully C. Antibody level and immunity against Hepatitis B virus infection among general dental practitioners. Acta Stomatol Naissi 2013; 29(67): 1273-78; doi: 10.5937/asn1367273P.

29. Wilson JD, Darby ML, Tolle SL, Sever JC Jr. Effects of occupational ultrasonic noise exposure on hearing of dental hygienists: a pilot study. J Dent Hyg 2002;76(4):262-9

30. Messano GA, Petti S. General dental practitioners and hearing impairment. J Dent 2012;40(10):821-8.

31. Petti S, De Giusti M, Moroni C, Polimeni A. Long-term survival curve of methicillin-resistant Staphylococcus aureus on clinical contact surfaces in natural-like conditions. Am J Infect Control 2012;40(10):1010-2.

32. Mikonranta L, Friman V-P, Laakso J. Life History Trade-Offs and Relaxed Selection Can Decrease Bacterial Virulence in Environmental Reservoirs. PLoS ONE 2012;7(8):e43801.

33. Dutil S, Veillette M, Meriaux A, Lazure L, Barbeau J, Duchaine C. Aerosolization of mycobacteria and legionellae during dental treatment: low exposure despite dental unit contamination. Environ Microbiol 2007;9(11):2836-43. 